\title{
Metallurgical Joining of Magnesium Alloys by the FSW Process
}

\author{
Tomáš Kupec ${ }^{1}$, Ivana Hlavačová ${ }^{2}$, Milan Turňa ${ }^{1}$ \\ ${ }^{1}$ Slovak University of Technology, Faculty of Materials Science $\& 3$ Technology, Department of Welding, \\ J. Bottu 25, 91724 Trnava, Slovakia \\ ${ }^{2}$ University of Žilina in Žilina, Faculty of Mechanical Engineering, Univerzitná 1, 01026 Žilina, Slovakia \\ Correspondence to: tomas.kupec@stuba.sk
}

\begin{abstract}
This paper deals with welding AZ 31Mg alloy by FSW (Friction Stir Welding) technology. Welds were fabricated with new equipment supplied from China for VUZ-PI Bratislava (Welding Research Institute - Industrial Institute). Welding parameters and conditions were proposed and tested. Joint quality was assessed by optical microscopy and microhardness measurements. The fabricated joints were sound, apart from minor inhomogeneities (cracks). It is considered that after certain adaptations of the welding parameters, and perhaps also of the welding tool, that this equipment will be capable of producing welded joints of excellent quality that can compete with any fusion welding technologies, including concentrated power sources.
\end{abstract}

Keywords: welding, magnesium alloy, friction stir welding, quality control.

\section{Introduction}

Magnesium alloys are applied mainly in the aviation, space, railway and shipbuilding industries, and also in general engineering [1]. Magnesium alloys are among the lightest structural materials. One of advantages of $\mathrm{Mg}$ alloys is therefore that theyreduce the weight of vehicles, which leads to a significant reduction in fuel consumption and in emissions $[6]$.

The principle of this technology is that a rotating tool with a specially designed pin on a shoulder is impressed into the gap between the welded materials, and is subsequently led in the weld line direction. Considerable heat is thus generated due to the friction and the plastic strain of the materials. The temperatures occurring in the weld zone usually attain 80 to $90 \%$ of the melting point of a given metal [4]. The principle of this technology is shown schematically in Figure 1.

The tool used in welding by the FSW process must be sufficiently strong, tough and resistant against wear in the welding process [3]. It must additionally have good oxidation resistance and a low coefficient of thermal conductivity, in order to minimize the thermal losses. Special steels and/or composite materials are selected for the pin material. Most of tools have a concave shape of the shoulder, and this acts as a release volume for the material displaced by the pin. The tool prevents material being forced out of from the sides of the pin shoulder, and de- sirable material forging under the tool is also preserved [2].

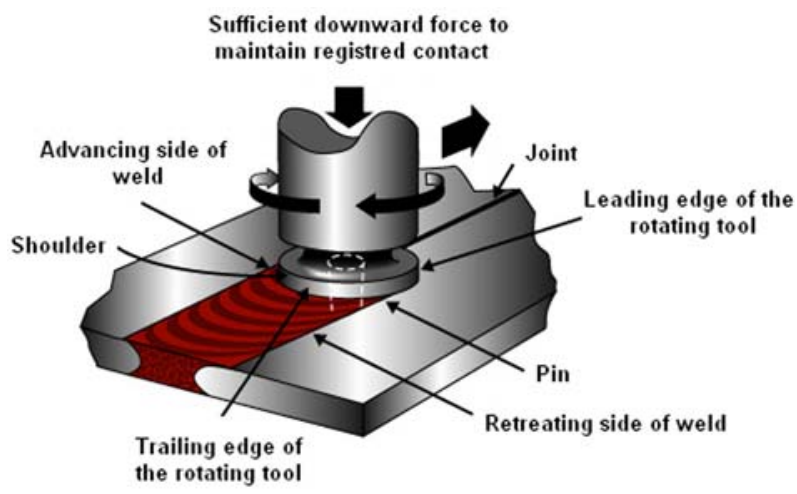

Figure 1: Schematic representation of the FSW process $[5]$

\section{Experimental}

An $\mathrm{Mg}$ alloy welding experiment was carried out in cooperation with WRI-II SR Bratislava, which has available newly-installed FSW equipment from China, see Figure 2.

The specimen of AZ $31 \mathrm{Mg}$ alloy, $100 \times 55 \times$ 10 mmin dimensions, was welded in the experiments. The chemical composition of this alloy is presented in Table 1. A weld of $\mathrm{AZ} 31 \mathrm{Mg}$ alloy is shown in Figure 3. 


\begin{tabular}{|l|}
\hline Equipment parameters: \\
\hline Equipment type: FSW - LM-060 \\
\hline Welding speed - max. $1500 \mathrm{~mm} / \mathrm{min}$. \\
\hline Compressive force - max. $12 \mathrm{t}$ \\
\hline Tool revolutions - $1500 \mathrm{rpm}$ \\
\hline Axis strokes - X: $2 \mathrm{~m}, \mathrm{Y}: 1 \mathrm{~m}, \mathrm{Z}: 0.4 \mathrm{~m}$ \\
\hline Power supply - $3 \mathrm{AC} 380 \mathrm{~V}, 50 \mathrm{~Hz}$ \\
\hline Current - $115 \mathrm{~A}$ \\
\hline Rated power - $60 \mathrm{~kW}$ \\
\hline
\end{tabular}

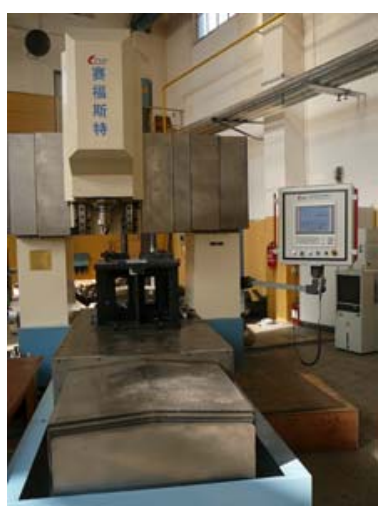

Figure 2: FSW - LM-060 welding equipment

Table 1: Chemical composition of AZ 31 alloy [6]

\begin{tabular}{|c|c|c|c|c|c|c|c|c|c|c|}
\hline Element & $\mathrm{Al}$ & $\mathrm{Zn}$ & $\mathrm{Mn}$ & $\mathrm{Si}$ & $\mathrm{Cu}$ & $\mathrm{Ni}$ & $\mathrm{Fe}$ & $\mathrm{Ca}$ & Other & $\mathrm{Mg}$ \\
\hline Wt. $\%$ & $2.5-3.5$ & $0.6-1.4$ & $0.2-0.6$ & $<0.05$ & $<0.008$ & $<0.002$ & $<0.008$ & $<0.02$ & $<0.03$ & balance \\
\hline
\end{tabular}

Welding parameters for the $\mathrm{Mg}$ alloy: tool revolutions $-800 \mathrm{rpm}$, welding speed $-100 \mathrm{~mm} / \mathrm{min}$, inclination angle of the tool $-3^{\circ}$, compressive force $-3.5 \mathrm{t}$.

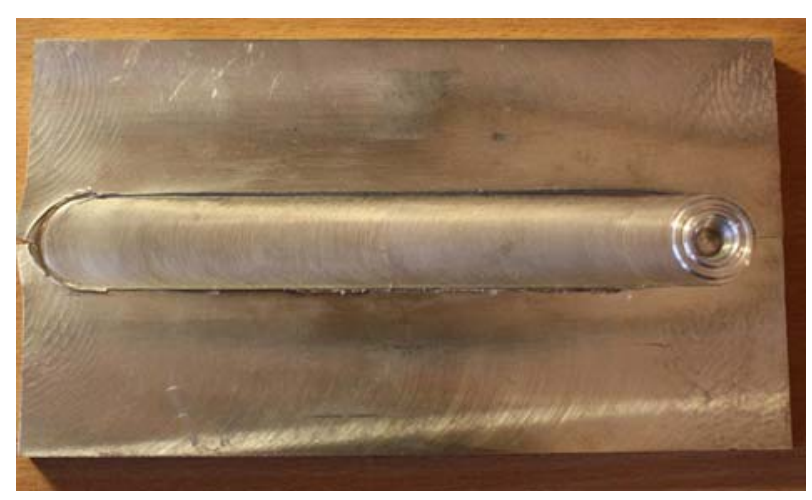

Figure 3: Weld of the $\mathrm{Mg}$ alloy fabricated by the FSW process

The samples for a metallographical study of the microstructure were prepared by a standard procedure which includes preparation, in this case by cold embedding the sample into epoxy resin, grinding the samples with emery papers of gradually finer granularity, followed by mechanical polishing with the application of a diamond paste with $3 \mu \mathrm{m}$ to $1 \mu \mathrm{m}$ grain size. The final polishing was performed by applying emulsion type OPS. The samples were etched by dipping in $1 \%$ Nital for $20 \mathrm{~s}$.

The microstructure of the base metal (Figure 4) is composed of a $\delta$ solid solution (a solid solution of $\mathrm{Al}$ in $\mathrm{Mg}$ ) and an intermediary $\gamma$ phase (Mg17Al12). When the Mg alloy is heated during welding and subsequent cooled down, crystallisation of eutectic cells occurred in the vicinity of the $\gamma$ - phase (Figure 5).

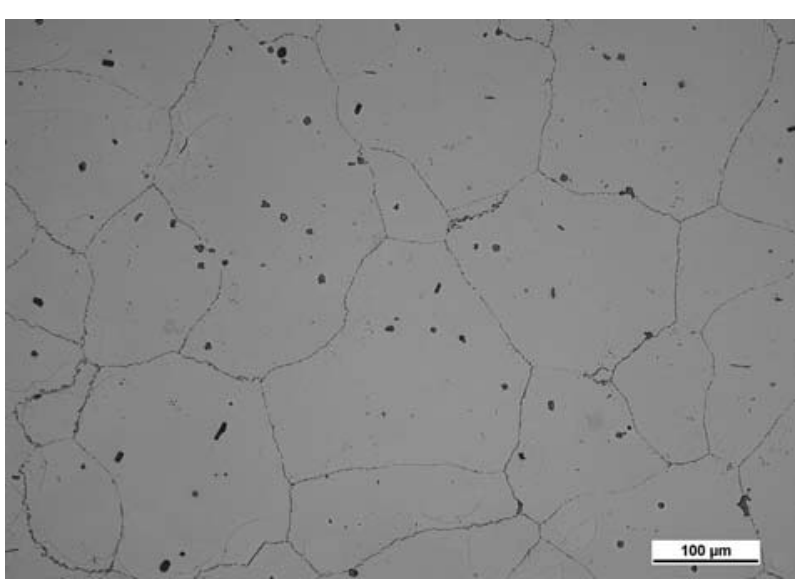

Figure 4: Microstructure of base metal (AZ31alloy), etch. $1 \%$ Nital

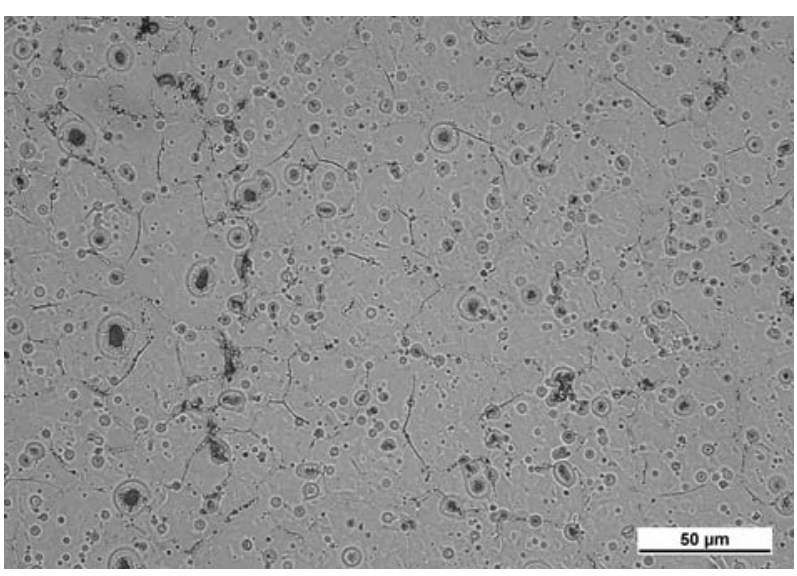

Figure 5: Microstructure of weld metal, etch. $1 \%$ Nital 


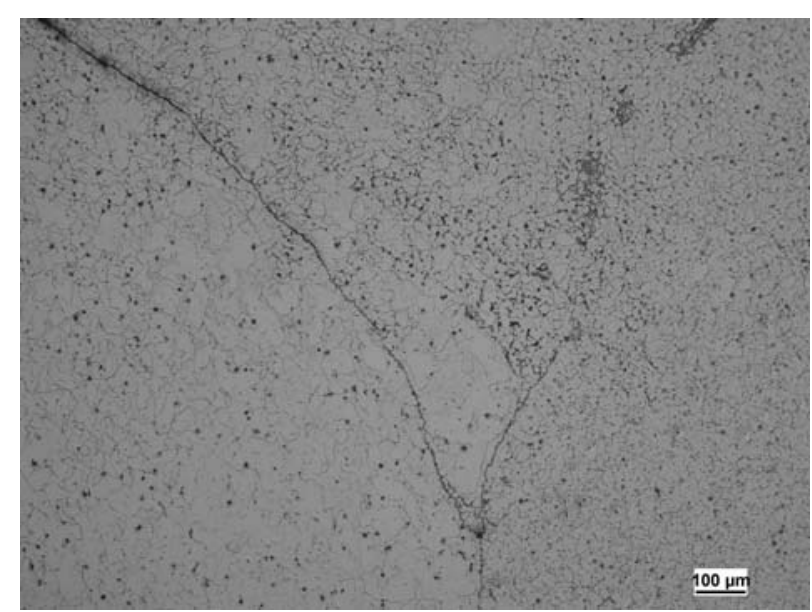

Figure 6: Boundary zone between the weld metal and the base metal (precipitated $\gamma$ - phase)

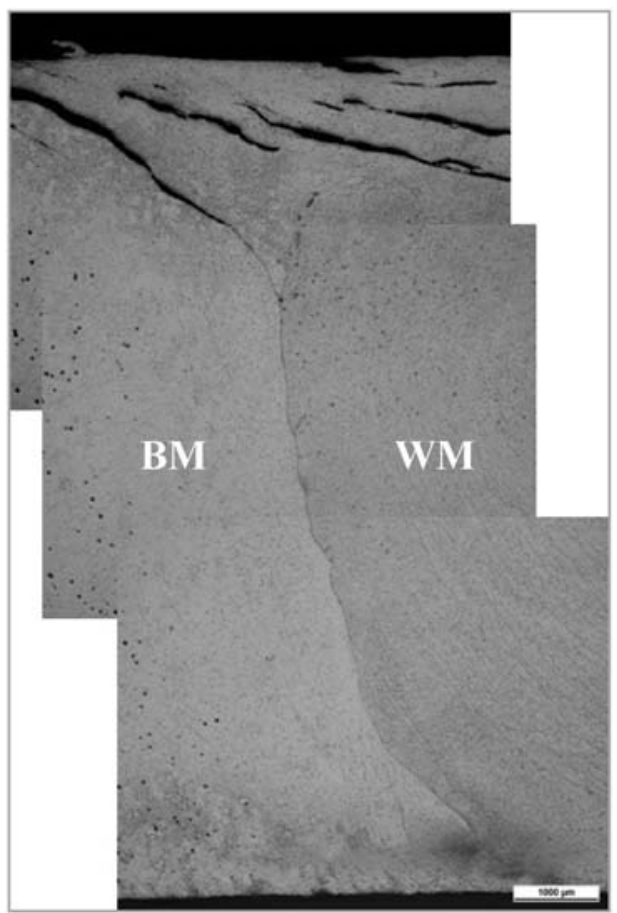

Figure 7: Boundary between the base metal and the weld metal

The transition zone between the base metal and the weld metal is characterized by a visible boundary
(Figure 6). Precipitation of the $\gamma$ - phase occurred on the weld metal — base metal boundary, see Figure 6 .

The base metals made a major contribution to the heat removal, since the weld metal was cooled down in the direction from the weld boundary to the welded base metals. A network of hot stress microcracks was probably formed on the weld surface.

The course of the microhardness was measured by a Vickers test using aZwick/Roellmicrohardness tester, applying a $500 \mathrm{~g}$ load acting on the cross section of the weld joint for $10 \mathrm{~s}$. Microhardness measurements typically show a great scatter of the measured values, since only a very small volume of material is involved. This means that the hardness value is considerably affected by microstructural factors (grain boundaries, inclusions, phase distribution etc.)

The distribution of the indents in the hardness measurement is shown in Figure 8, and the course of the microhardness is shown in Figure 9. We may conclude that the microhardness values of the weld metal, the heat affected zone (HAZ) and the base metal do not differ significantly.

\section{Conclusions}

This paper has presented a brief survey of the metallurgy of welding $\mathrm{Mg}$ alloys using the FSW process. The welding was performed on Chinese-produced FSW - LM-060 equipment, which is at present installed at the Welding Research Institute - Industrial Institute of the Slovak Republic with its seat in Bratislava. AZ $31 \mathrm{Mg}$ alloy was used: the chemical composition is given in Table 1 . The selected welding parameters and conditions have not yet been fully optimized, since defects such asmicrocracks were observedin several places. It will therefore be necessary to adapt the welding parameters and perhaps also the shape and inclination of the welding tool in future experiments. A metallographic assessment of the welded joints revealed the actual phases of the $\mathrm{Mg}$ alloy. The measured microhardness values in the base metal, HAZ and weld metal did not differ considerably. It can be supposed that this technology will be very suitable for high-quality welding of $\mathrm{Mg}$ alloys.

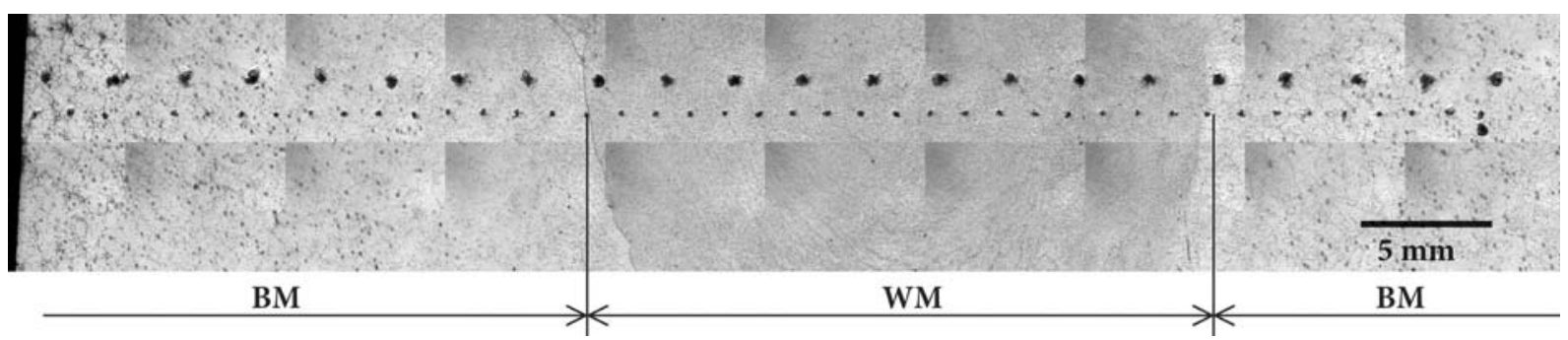

Figure 8: Distribution of indents for the microhardness measurement across the weld metal — base metal boundary 


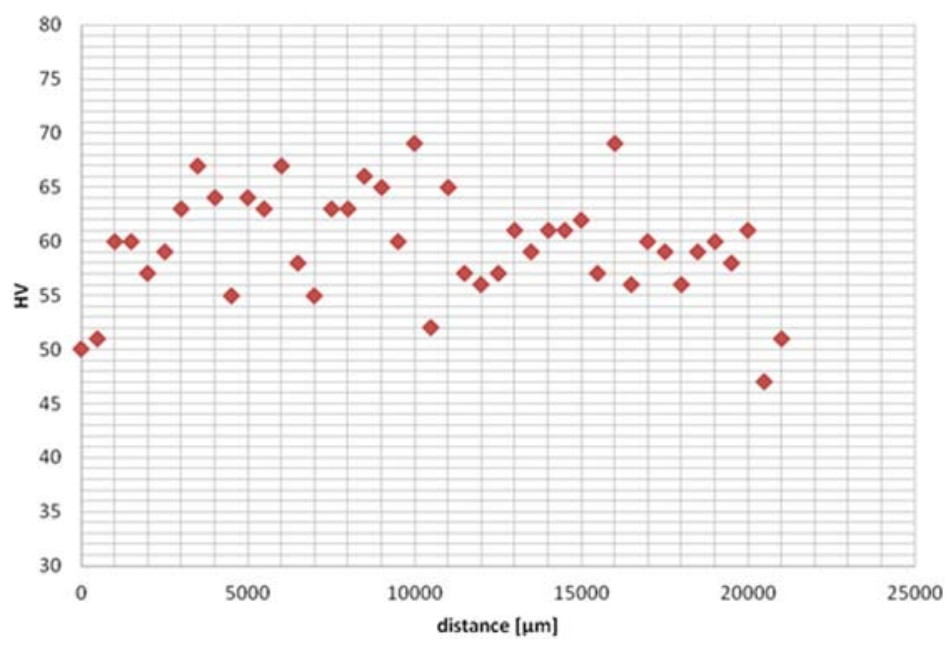

Figure 9: Course of microhardness in a weld joint across the weld metal — base metal boundary

\section{Acknowledgement}

This paper reports on work carried out with support from the Grant Agency VEGA MŠVVŠ SR, in the framework of project No. 1/2594/12 Study of Metallurgical Joining and Other Technological Processes of Ecologically Friendly Technologies.

\section{References}

[1] Friction Stir Welding. Technical Handbook. ESAB2011.

[2] Hrivňák, I.: Zváranie a zvaritě̌noš̌materiálov (Welding and Weldability of Materials). Trnava : STU, 2011. ISBN 978-80-227-3167-6.
[3] Accessible on: http://www.twi.co.uk/technologies/ welding-coating-and-materialprocessing/ friction-stir-welding/

[4] Mishra, R. S., Mahoney, M. W.: Friction Stir Welding and Processing. USA : ASM International, 2007, 360 p. ISBN 978-0-87170-840-3.

[5] FrictionStirLink. Accessible on: http://www.frictionstirlink.com/desc.html

[6] Kainer, K .U.: Magnesium. In Proceed. of 7th International Conf. on $\mathrm{Mg}$ Alloys and their Applications. Weinheim : Wiley - VCH Verlag GmbH \& Co. KG and A. 284MO67538, 2007.

[7] Turňa, M.: Solid State Special Welding Methods. Lectures. IIW postgraduate study. Prague : 2011. 